\title{
Design and Performance of Continuously Reinforced Concrete Pavements
}

\author{
ELDON J. Yoder \\ Research Engineer \\ and \\ AsIF FAIZ \\ Research Assistant \\ Joint Highway Research Project \\ Purdue University
}

\section{INTRODUCTION}

During the past several years, many states have built continuously reinforced concrete pavements. It is of interest to note that the first continuously reinforced concrete pavement was built in 1938 on U.S. 40 near Stilesville, Indiana

Up to the year 1958, continuously reinforced pavements in the United States included the first pavements built in Indiana, experimentation pavements built in New Jersey in 1947, Illinois in 1947, California in 1949, and Texas pavements constructed in 1951, 1955 and 1957. Pennsylvania also constructed two test sections in 1956 and in 1957.

Since 1958, the use of continuously reinforced concrete pavements in highway construction has been on the increase and up to the present time there have been about 10,000 miles constructed in the United States. One of the primary reasons for constructing this type of pavement is that it is smoother than ordinary pavements and experience has shown that in most cases it requires less maintenance.

\section{DESIGN CONCEPTS}

Temperature reinforcement, as used in jointed pavements, is used for the purpose of controlling the width of crack opening to insure adequate load transfer across a crack. The amount of steel required for this is relatively small and, therefore, little additional structural capacity results from the use of this steel. The required steel reinforcement for temperature control is dependent upon length of slab. As the length of 
the slab increases, the required amount of temperature steel also increases.

A continuously reinforced concrete pavement is one in which no transverse joints are used other than expansion joints at bridges and other structures and construction joints that are used at the end of a day's pour. The continuously reinforced concrete pavement contains relatively high amounts of steel normally ranging between 0.5 and 0.8 percent of the cross-sectional area.

In continuously reinforced concrete pavements, cracks may develop from a variety of causes including shrinkage, contraction, warping and load. Experience has shown that a large number of cracks form very soon after placing the concrete. These particular cracks are probably caused by a combination of shrinkage, contraction and warping stresses.

Figure 1 demonstrates the hypothesis which explains the matter of crack formation in continuously reinforced concrete pavements. Considering first shrinkage and contraction, cracks may develop as a result of restrained movement caused by temperature changes or by shrinkage of the concrete during the curing process. As the concrete tends to contract, friction forces are developed between the pavement and the subgrade.

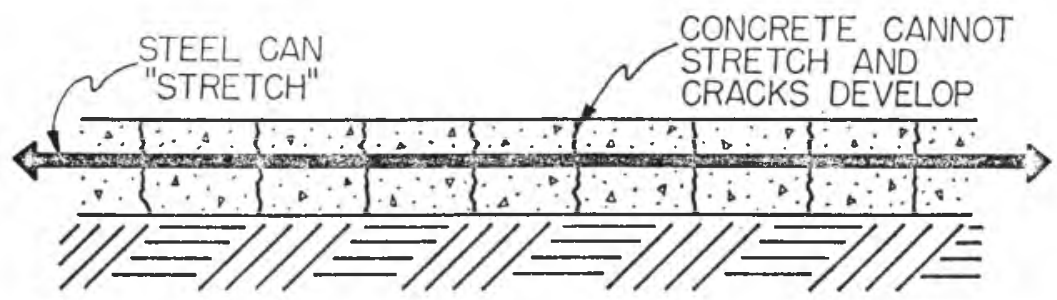

Fig. 1. Crack Formation in CRCP

Since the steel has a higher modulus of elasticity than the concrete, the concrete is overstressed and subsequent cracks develop. Extreme temperature drops are conducive to rapid crack development soon after the pavement is constructed. The important factor to consider regarding the matter of crack formation on this type of pavement is that the cracks are relatively close together (compared to normal jointed pavements) but the large amount of steel in the pavement holds these cracks close together and load transfer is then brought about by grain interlock.

Hence, continuously reinforced concrete pavement by its very nature cracks at close intervals. The pavement must contain sufficient longitudinal steel to prevent these cracks from opening to any degree. The success of the pavement depends upon the steel to carry out its intended function. 


\section{EX'TENT OF CON'TINUOUSLY REINFORCED PAVEMENTS IN INDIANA}

Figure 2 shows the amount of continuously reinforced concrete pavement constructed in Indiana up to the summer of 1972. The first pavement, as was mentioned previously, was built on an experimental basis in 1938. Since that time several short sections of pavement were constructed in the mid-60's. During the past several years many additional miles of continuously reinforced pavement have been built, primarily on the interstate system.

Most of the pavements constructed in Indiana are nine inches thick although some have been constructed seven and eight inches in thickness. For the most part, nonstabilized granular subbases have been used under the pavement, although in recent years design has included the use of asphalt-treated subbases in most situations.

Various types of steel placement and construction (formed or slipformed) have been used. The percentage of steel used has been 0.6 percent of a cross-sectional area irrespective of the other factors of design.

\section{PERFORMANCE OF CONTINUOUSLY REINFORCED CONCRETE PAVEMENTS IN INDIANA}

To evaluate the performance of CRC pavements in Indiana, a statewide condition survey was conducted in late 1972. The field survey was a cooperative venture in which personnel from Purdue University were assisted by the Research and Training Center and the Crawfordsville District Office. A sampling procedure was used to design the field survey and statistical methods were used to analyze the resulting data. On the basis of the statistical analysis, a study of the factors influencing CRC pavement performance was made.

\section{Study Design}

Figure 2 shows the distribution of CRC pavements in Indiana. The primary intent of the study design was to insure the inclusion of every CRCP contract that had been completed up to the time of the survey in the study. To this effect, a stratified random sample of CRC pavements was used in the field survey. Each unit of evaluation or survey section was a 5,000-foot length of pavement, but care was taken that a randomly selected pavement section did not coincide with the exact end or beginning of a construction contract.

The sections were stratified on the basis of the following factors:

1. Contract number,

2. Thickness of concrete slab, 


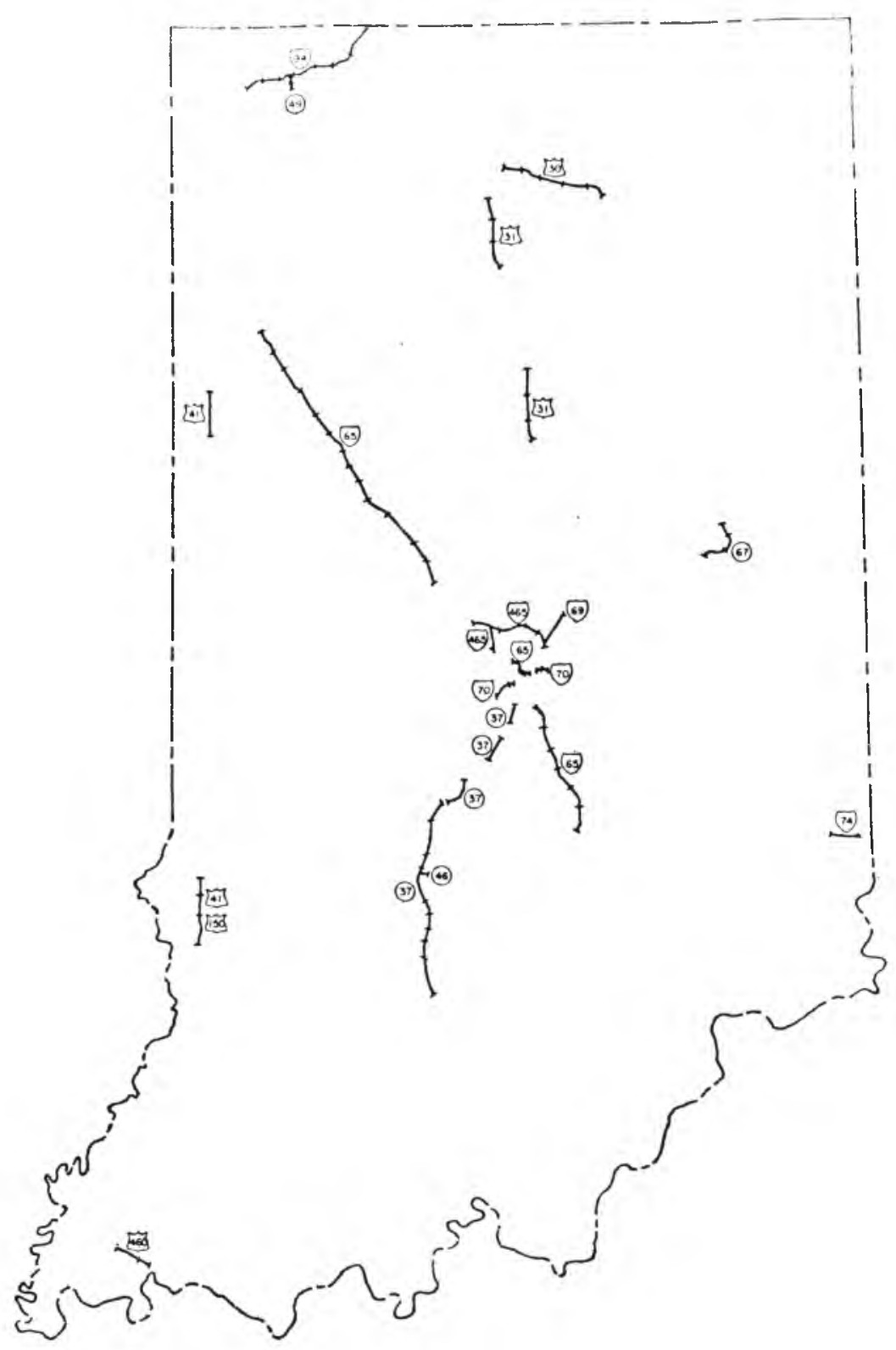

Fig. 2. CRC Pavements in Indiana Summer 1972

3. Method of paving (slipformed or sideformed),

4. Method of steel placement (preset on chairs or depressed),

5. Method of steel fabrication (loose bars, welded wire fabric, or bar mats), 
6. Type of subbase (gravel, slag, crushed stone or bituminous stabilized subbase),

7. Subgrade type (fine-grained or granular).

Table 1 indicates this stratification scheme.

TABLE \& FACTORIAL DESIGN FOR STUDY OF FACTORS INFLUENCING CRCP PERFORMANCE

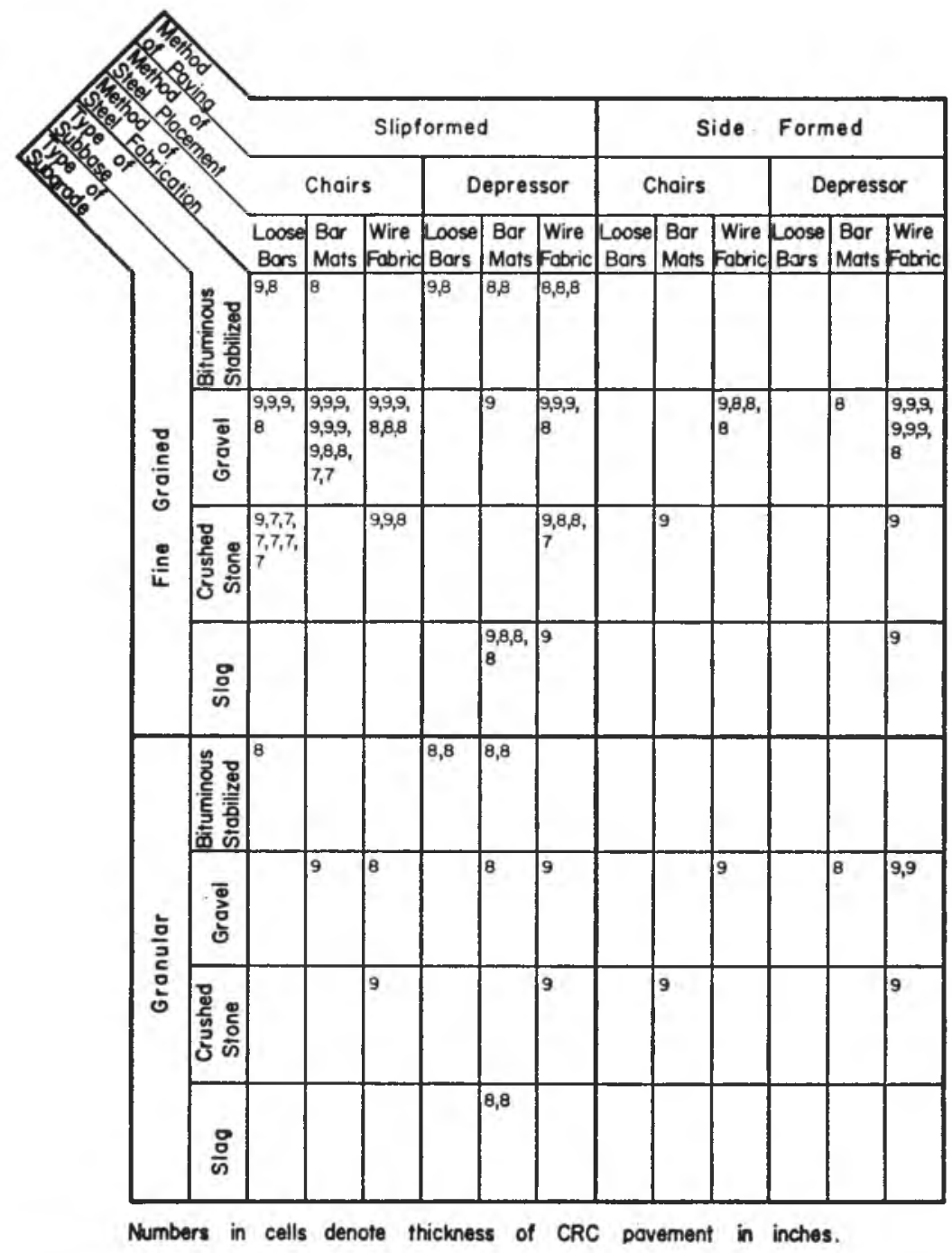


The data relative to these factors were obtained from construction survey records. In addition, information pertaining to concrete slump, the date of paving, and the date a section was opened to traffic was also taken from construction records.

It is to be noted that most of the pavements were nine inches thick, although several were eight inches thick and nine of the sections had a thickness of seven inches.

In certain cases, more than one survey section was included in a particular contract. This apparent duplication resulted whenever a contract section crossed more than one level of another stratification factor. For example, if two subgrade types occurred over one contract, two samples were taken. Similarly, two sample sections were surveyed if two different methods of steel placement were used within a particular contract. Consequently, a total of $89 \mathrm{CRCP}$ sections were used in the condition survey.

A provision was made in the study design so that some of the sections would be surveyed twice by different survey teams.

The contracts included in the study design were the ones that had been constructed up to the time of the field survey. Therefore, some of the later contracts that were completed during or after the survey period could not be incorporated into the study.

\section{Variables Evaluated in the Field Survey}

Features of the highway which were logged were determined on the basis of data previously obtained from the surveys made on I-65. Table 2 shows a listing of the defects (and other features) that were logged by the field survey teams. The primary distress factors included parallel cracks, random cracks, area and number of defects as noted by patching, etc.

Regarding parallel cracks, only those having a spacing closer than 30 inches were considered. Parallel cracks and random cracks were logged on the basis of linear feet of longitudinal pavement containing the particular type of crack under consideration.

Defects were noted as either severely distressed areas or those areas that had been previously patched with asphalt or portland cement concrete. The defects were logged on the basis of the observed number of defects and the estimated area of defects per section.

In addition to the above, information relative to grade, curvature, pumping and general data on the physical features of the highway were cataloged. Wherever patches and breakups were observed, sketches of these were made and the exact locations thereof were noted on the log sheets. 


\section{TABLE 2. DATA OBTAINED DURING FIELD STUDY, CRC PAVEMENTS}

1. Position at Grade: [F(fill), C(cut), A (at grade)].

2. Curvature: [T(tangent), CR(curve to right), CL (curve to left)]. Curvature was evaluated relative to the direction of traffic.

3. Pumping: Estimated in terms of the length of section that showed pumping. Pumping was identified by 1) observing discoloration (mud-marks) on the shoulder, 2) observing wet areas on the shoulder.

4. Crack Patterns: Parallel type (less than 30-in. spaced), random type I (diagonal, Y-cracks, etc.), and random type II (combined parallel and diagonal) crack patterns were observed in terms of longitudinal length of pavement.

5. Crack Counts: Spalled cracks were counted in terms of three categories: $\mathrm{S}$ (slight), $\mathrm{M}$ (moderate), and $\mathrm{H}$ (heavy).

6. Breakups and Asphalt Patches: These were counted and also estimated in terms of area. Both length and width dimensions were indicated ( $W \times L)$ in feet.

7. Concrete Patches: These were counted and also estimated in terms of area. Both length and width of the patch were indicated in feet $(W \times L)$.

8. Crack patterns where breakups and patches occurred were also indicated in terms of length of pavement.

9. Each breakup or a patch together with its accompanying crack pattern and spalling characteristics was sketched on the survey form. Some of these defects were photographed.

10. Any dates marked on the pavement were recorded.

11. Joints (construction or expansion) were sketched and indicated by a station identification.

12. Identification features such as bridges, interchanges, etc. were indicated by a station identification. Remarks relative to unusual soil characteristics (subgrade) were also recorded.

\section{ANALYSIS AND RESULTS}

The data obtained from the statewide CRCP study were statistically analyzed by using a weighted least squares analysis of variance procedure. This procedure was necessitated because of unequal subclass cell frequencies in the data. In this situation, the different comparisons with which the sums of squares are associated become nonorthogonal and usual analysis of variance leads to biased test procedures.

The ANOVA results reported in this study were obtained by using LSMLGP (Least Squares and Maximum Likelihood General Purpose Program), a computer program at the Purdue University Computer Center. This program utilizes a general weighted least squares proce- 
dure and can be used for missing value problems, where cell frequencies are unequal, and also, where data are not available for certain subclasses. The program only handles main effects and two-factor interactions, but has provisions for incorporating covariates (continuous variables) in the analysis.

To study the effect of factors influencing the performance of CRC pavements, the following analysis of variance model was used.

where

$$
\begin{aligned}
\mathrm{Y}_{\mathrm{ijk} l \mathrm{mp}}= & \mu+\mathrm{A}_{\mathrm{i}}+\mathrm{B}_{\mathrm{j}}+\mathrm{C}_{\mathrm{k}}+\mathrm{D}_{l}+\mathrm{F}_{\mathrm{m}}+\mathrm{AB}_{\mathrm{ij}}+\mathrm{AC}_{\mathrm{ik}}+\mathrm{AD}_{\mathrm{il}} \\
& +\mathrm{AF}_{\mathrm{im}}+\mathrm{BC}_{\mathrm{jk}}+\mathrm{BD}_{\mathrm{jl}}+\mathrm{BF}_{\mathrm{jm}}+\mathrm{CD}_{\mathrm{k} l}+\mathrm{CF}_{\mathrm{km}}+ \\
& \mathrm{DF}_{l \mathrm{~m}}+\beta_{1}\left(\mathrm{~S}_{\mathrm{ijk} l \mathrm{mp}}-\overline{\mathrm{S}}\right)+\beta_{2}\left(\mathrm{~T}_{\mathrm{ijklmp}}-\overline{\mathrm{T}}\right)+\epsilon_{(\mathrm{ijk} l \mathrm{~m}) \mathrm{p}}
\end{aligned}
$$

$\mathrm{Y}_{\mathrm{ijklmp}}=$ measured variable, e.g., no. of defects,

$\mu=$ true mean effect for the population,

$A_{1}=$ true effect of method of paving (slipformed vs. sideformed),

$B_{j}=$ true effect of method of steel placement (depressor vs. chairs),

$\mathrm{C}_{\mathrm{k}}=$ true effect of method of steel fabrication (bar mats vs. wire fabric vs. loose bars),

$\mathrm{D}_{l}=$ true effect of type of subbase (bituminous stabilized vs. crushed stone vs. slag vs. gravel),

$\mathrm{F}_{\mathrm{m}}=$ true effect of subgrade soil (ganular vs. fine-grained),

$\mathrm{S}_{\mathrm{ljk} l \mathrm{mp}}=$ linear effect of the covariate, slump (in.),

${ }^{*} \mathrm{~T}_{\mathrm{ijk} l \mathrm{mp}}=$ linear effect of covariate, number of months of traffic,

$\beta_{1}, \beta_{2}=$ regression coefficients,

$\overline{\mathrm{S}}, \overline{\mathrm{T}}=$ mean value of slump and traffic respectively, $\epsilon_{(\mathrm{ijk} l m)_{\mathrm{p}}}=$ true error, $\operatorname{NID}\left(\mathrm{o}, \sigma^{2}\right)$.

The other terms denote the two-factor interactions between the factors, $A, B, C, D$ and $F$. The subscripts assume the values:

$$
\begin{aligned}
\mathrm{i}= & 1,2 \\
\mathrm{j}= & 1,2 \\
\mathrm{k}= & 1,2,3 \\
l= & 1,2,3,4 \\
\mathrm{~m}= & 1,2 \\
\mathrm{p}= & 0 \text { (missing value), or } \\
& 1,2 \ldots \mathrm{n}_{\mathrm{ijk} l \mathrm{~m}} \text { (unequal subclass numbers). }
\end{aligned}
$$

The model does not take into consideration three-factor and higher order interaction owing to computer program limitations. Consequently,

* This variable, that is the number of months since the pavement section was opened to traffic, was used as an indirect measure of load applications. 
these interaction effects are confounded with the error effect in this formulation.

In analyzing some of the measured variables, a square-root transformation was applied to the data to satisfy the requirement of homogeneity of variance, a basic assumption underlying the analysis of variance procedure. The Foster-Burr, Q-Test was used for testing homogeneity of variance. Effects that were nonsignificant at an $a$-level of 0.25 were pooled with the error effect and tests of significance were made using the pooled error term.

Table 3 summarizes the results of analysis of variance. The dependent variables used in the analysis were:

1. Square root of number of asphalt patches, concrete patches and breakups per section,

2. Square root of number of asphalt patches and breakups per section,

3. Square root of area of asphalt patches and breakups in square feet per section,

4. Square root of moderately spalled cracks per section,

5. Length of pavement showing parallel cracking and length of pavement showing random cracking, in feet per section.

The above variables are defined in Table 2. The extent of pavement distress was evaluated in terms of number of defects while the magnitude of the distress was determined by estimating the area of defects. Asphalt patches and breakups were considered separately as these manifest recent pavement distress. Concrete patches were included in only one evaluation scheme, since it was not exactly known when the concrete patches were placed.

Factors Affecting Pavement Distress as Evaluated by Number and Area of Defects

It is indicated by the results of the analysis of variance shown in Table 3 that:

1. The method of steel fabrication and subbase type together with concrete slump have a significant effect on pavement distress as evaluated by the number of defects (concrete patches, asphalt patches and breakups) observed per section.

2. The method of steel fabrication, the type of subbase, traffic and the interaction between the methods of paving and placement of steel reinforcement have a significant influence on pavement distress as determined by the number of asphalt patches and breakups observed per section. 


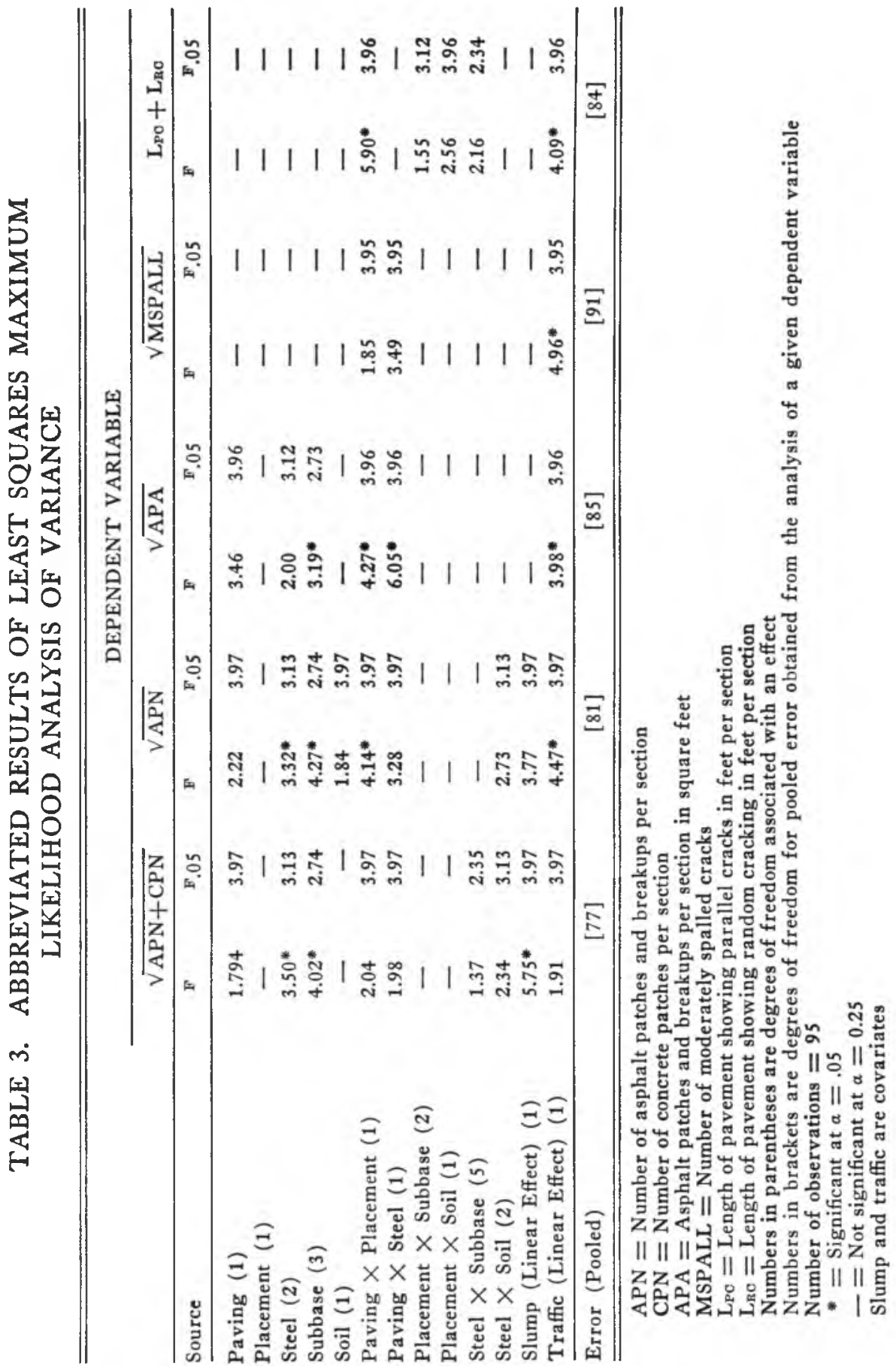


3. If estimated area of asphalt patches and breakups per section is used as a measure of the magnitude of distress, it is observed that traffic, the type of subbase, the interaction between the methods of paving and placement of steel reinforcement, and the interaction between the methods of paving and steel fabrication significantly explain the variance in the estimated area of asphalt patches and breakups per section.

4. Irrespective of the dependent variable, subgrade type does not appear to have a significant effect on pavement distress.

Factors Affecting Pavement Cracking

Table 3 further indicates that:

1. Moderately spalled cracks are primarily induced by traffic.

2. The extent of parallel cracks and random cracking per section of pavement is significantly influenced by traffic and the interaction between methods of paving and placement of steel reinforcement.

\section{Detailed Study of Factors Influencing Performance of CRC Pavements}

Tables 4 and 5 further elucidate the results of analysis of variance shown in Table 3 and were developed on the basis of these results. In these tables, two separate columns are provided to show the effect of including the data from contracts R-7935 and R-6023. These contracts were treated separately because the contract R-7935 (I-65) developed distress shortly after it was opened to traffic, while contract $\mathrm{R}-6023$ (I-74) is the oldest CRCP contract (1964) included in this study.

1. Effect of Subgrade. The analyses indicate that subgrade soil type had no significant effect on pavement distress or the extent of observed cracking.

2. Effect of Subbase. The results of data analysis clearly show that subbase type has a major influence on pavement distress. Table 4 demonstrates the effect of subbase on CRCP performance. It is indicated that the use of bituminous stabilized and crushed stone subbases resulted in significantly better performance than the use of gravel subbases. It was also observed that sections with gravel subbases showed a higher incidence of pumping.

Relative to the comparative performance of bituminous stabilized and crushed stone subbases, sections with bituminous stabilized subbases did not show any significant distress while some sections with crushed stone subbases showed minor distress. This conclusion should be viewed with caution as bituminous stabilized subbases were used more recently 
TABLE 4. EFFECT OF SUBBASE ON THE

DISTRIBUTION OF AVERAGE

DEFECTS PER SECTION

\begin{tabular}{|c|c|c|c|c|c|}
\hline & \multicolumn{5}{|c|}{ Type of Subbase } \\
\hline & \multicolumn{2}{|c|}{ Gravel } & Slag** & \multirow{2}{*}{$\begin{array}{c}\begin{array}{c}\text { Crushed } \\
\text { Stone }\end{array} \\
0.15 \\
(20)\end{array}$} & \multirow{2}{*}{$\begin{array}{c}\begin{array}{r}\text { Bituminou } \\
\text { Stabilized }\end{array} \\
0.00 \\
(15)\end{array}$} \\
\hline $\begin{array}{l}\text { Avg. No. of Concrete } \\
\text { Patches, Asphalt Patches } \\
\text { and Breakups per Section }\end{array}$ & $\begin{array}{l}1.42 * \\
(46)\end{array}$ & $\begin{array}{l}0.80 \\
(44)\end{array}$ & $\begin{array}{r}0.75 \\
(8)\end{array}$ & & \\
\hline $\begin{array}{l}\text { Avg. No. of Asphalt } \\
\text { Patches and Breakups } \\
\text { per Section }\end{array}$ & $\begin{array}{l}1.08 * \\
(46)\end{array}$ & $\begin{array}{l}0.74 \\
(44)\end{array}$ & $\begin{array}{l}0.62 \\
(8)\end{array}$ & $\begin{array}{l}0.15 \\
(20)\end{array}$ & $\begin{array}{r}0.00 \\
(15)\end{array}$ \\
\hline $\begin{array}{l}\text { Avg. No. of Concrete } \\
\text { Patches per Section }\end{array}$ & $\begin{array}{l}0.34^{*} \\
(46)\end{array}$ & $\begin{array}{l}0.06 \\
(44)\end{array}$ & $\begin{array}{l}0.13 \\
(8)\end{array}$ & $\begin{array}{r}0.00 \\
(20)\end{array}$ & $\begin{array}{r}0.00 \\
(15)\end{array}$ \\
\hline $\begin{array}{l}\text { Avg. Area of Concrete } \\
\text { Patches, Asphalt Patches } \\
\text { and Breakups per Section } \\
\text { in Square Feet }\end{array}$ & $\begin{array}{c}89.03 * \\
(46)\end{array}$ & $\begin{array}{r}48.37 \\
(44)\end{array}$ & $\begin{array}{c}35.25 \\
(8)\end{array}$ & $\begin{array}{r}1.60 \\
(20)\end{array}$ & $\begin{array}{r}0.00 \\
(15)\end{array}$ \\
\hline $\begin{array}{l}\text { Avg. Area of Asphalt } \\
\text { Patches and Breakups } \\
\text { per Section in Square } \\
\text { Feet }\end{array}$ & $\begin{array}{c}57.00 * \\
(46)\end{array}$ & $\begin{array}{r}42.83 \\
(44)\end{array}$ & $\begin{array}{r}29.25 \\
(8)\end{array}$ & $\begin{array}{l}1.60 \\
(20)\end{array}$ & $\begin{array}{r}0.00 \\
(15)\end{array}$ \\
\hline $\begin{array}{l}\text { Avg. Area of Concrete } \\
\text { Patches per Section } \\
\text { in Square Feet }\end{array}$ & $\begin{array}{c}32.03 * \\
(46)\end{array}$ & $\begin{array}{l}5.54 \\
(44)\end{array}$ & $\begin{array}{r}6.00 \\
(8)\end{array}$ & $\begin{array}{r}0.00 \\
(20)\end{array}$ & $\begin{array}{r}0.00 \\
(15)\end{array}$ \\
\hline
\end{tabular}

(primarily 1972) and have not been exposed to the full range of environmental and traffic conditions.

The above conclusions also hold true relative to the magnitude of distress as evaluated by the area of defects.

3. Effect of Type of Steel Reinforcement. Table 5 indicates the distribution of average number and area of defects, average number of moderately spalled cracks and average length of cracking observed per pavement section for various combinations of construction factors.

From the results presented in this table, it may be concluded:

a) That use of bar mats resulted in more defects per section than the use of wire fabric or loose bars. This statement should be qualified by the fact that use of bar mats was confined primarily to older CRCP contracts while the use of loose bars is more recent (primarily 1972). 


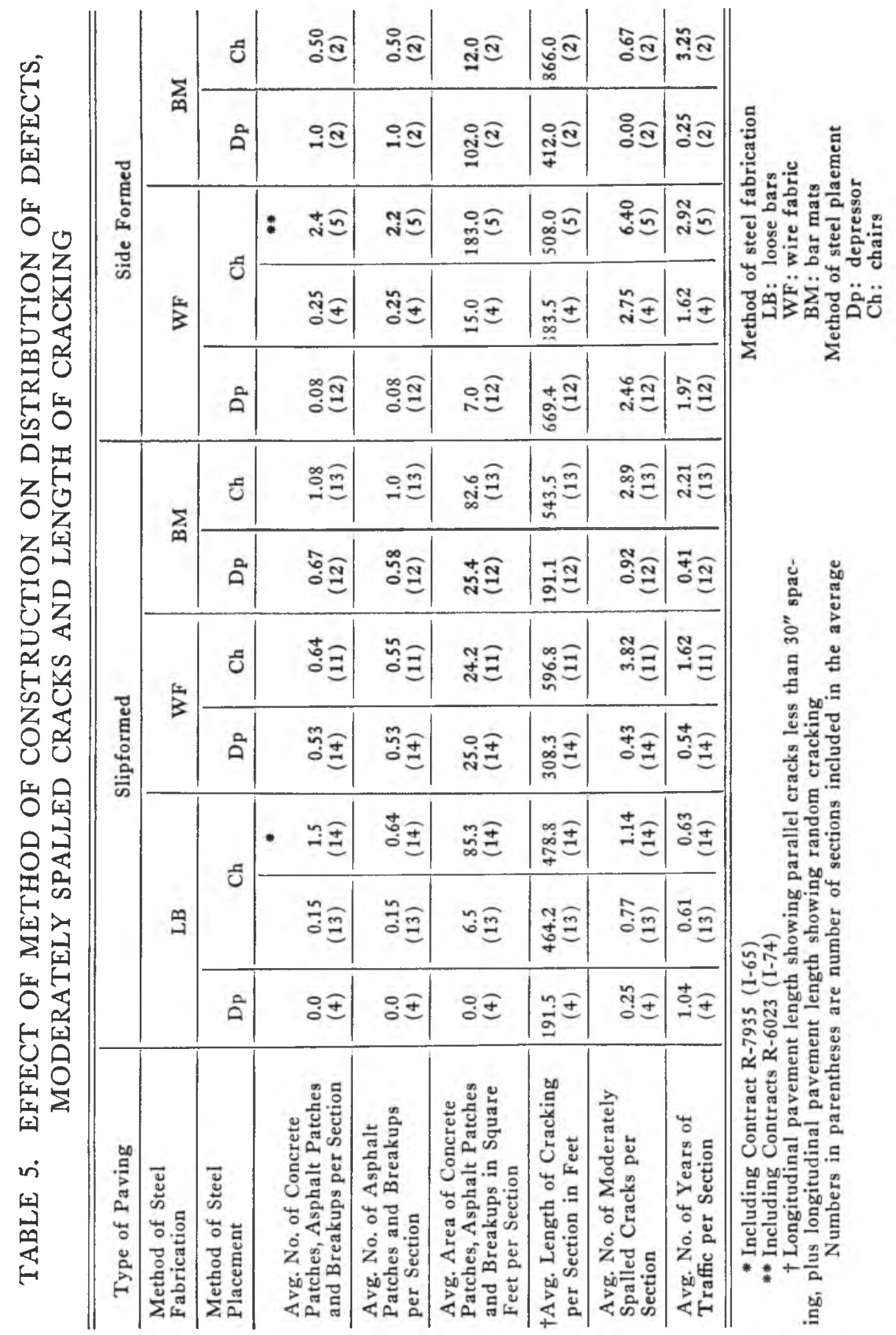


b) For various combinations of methods of paving and steel placement, use of wire fabric resulted in more widespread cracking.

c) The use of wire fabric resulted in relatively more distress in slipformed pavement sections than in side formed sections.

4. Effect of Method of Steel Placement. For various combinations of steel type and paving method, it would be noticed in Table 5 that a larger number of defects per section was observed where chairs were used as a method of placement. This relationship breaks down in one case where a combination of a side formed pavement with bar mats was used. Here the use of a depressor resulted in a relatively larger number of defects. More cracking was also evidenced in sections where chairs were used for placing steel reinforcement. This relationship does not hold for the case where a side formed pavement with wire fabric type steel reinforcement was used. In this case, use of a depressor resulted in a greater amount of cracking.

5. Effect of Method of Paving. Table 5 shows that, by itself, the method of paving has no significant effect on pavement distress. Relative to pavement cracking, it is indicated that the incidence of cracking was relatively greater in side formed pavements as opposed to slipformed pavements for various combinations of steel reinforcement and method of steel placement.

6. Effect of Traffic. The time that a pavement has been under traffic has a significant effect on pavement distress.

7. Effect of Concrete Slump. Table 6 indicates the effect of slump on distribution of defects, where defects are defined as the number of concrete patches, asphalt patches, and breakups per section. It may be concluded from Table 6 that a higher percentage of sections had defects where the concrete slump was low. From this table, it further appears that the optimum value of slump relative to performance is between 2.0-2.5 inches. With increase in slump, a decrease in the number of defects per section is also indicated. The effect of slump values, greater than 2.5 inches, on the occurrence of defects should be carefully considered. There were only six sections having slump values greater than 2.5 inches and these may not be representative of the effect.

\section{Distribution of Defects}

Figure 3 shows the frequency distribution of defects observed in the statewide CRCP survey where defects are defined as the number of concrete patches, asphalt patches and breakups. This distribution shows that: 


\section{TABLE 6. EFFECT OF SLUMP ON DISTRIBUTION OF DEFECTS}

(Concrete Patches, Asphalt Patches and Breakups)

\begin{tabular}{lccccc}
\hline $\begin{array}{c}\text { Slump } \\
\text { (inches) }\end{array}$ & $\begin{array}{c}\text { Number of } \\
\text { Sections } \\
\text { Surveyed }\end{array}$ & $\begin{array}{c}\text { Number of } \\
\text { Sections With } \\
\text { No Defects }\end{array}$ & $\begin{array}{c}\text { Number of } \\
\text { Sections } \\
\text { With Defects }\end{array}$ & $\begin{array}{c}\text { Percent of } \\
\text { Sections } \\
\text { With Defects }\end{array}$ & $\begin{array}{c}\text { Number of } \\
\text { Defects Per } \\
\text { Section* }\end{array}$ \\
\hline $1.0-1.5$ & 31 & 17 & 14 & $42.2 \%$ & 2.9 \\
$1.5-2.0$ & 39 & 29 & 10 & 25.6 & 3.2 \\
$2.0-2.5$ & 13 & 11 & 2 & 15.4 & 1.0 \\
$2.5-3.0$ & 4 & 3 & 1 & 25.0 & 1.0 \\
$>3.0$ & 2 & 2 & 0 & 0.0 & 0.0 \\
\hline \hline
\end{tabular}

* Only considering sections with defects.

1. 69.7 percent of CRCP sections surveyed did not show any defects.

2. 26.9 percent of CRCP sections had from one to five defects per section.

3. 3.4 percent of CRCP sections had more than five defects per section.

This information was based on 89 sections, each 5,000 feet long. This amounted to 84.28 miles of CRC pavement length.

\section{CONCLUSIONS}

Based upon a statistical analysis of data collected during a statewide survey of continuously reinforced concrete pavements in Indiana the following conclusions are presented. It should be kept in mind that the survey was statistically designed wherein each contract was required to be in the study, but samples were obtained (5,000 feet in length) within each contract section. In some cases, more than one 5,000 foot section was observed within a contract section because of the stratification used in the statistical study.

The results of the statewide survey have given some definite indications as will be pointed out below. However, several questions remain unanswered relative to the reasons for distress on certain CRCP sections in the state.

\section{Significant Factors Affecting Performance}

The following conclusions pertain to the effect of various factors influencing the performance of CRC pavements in Indiana. 


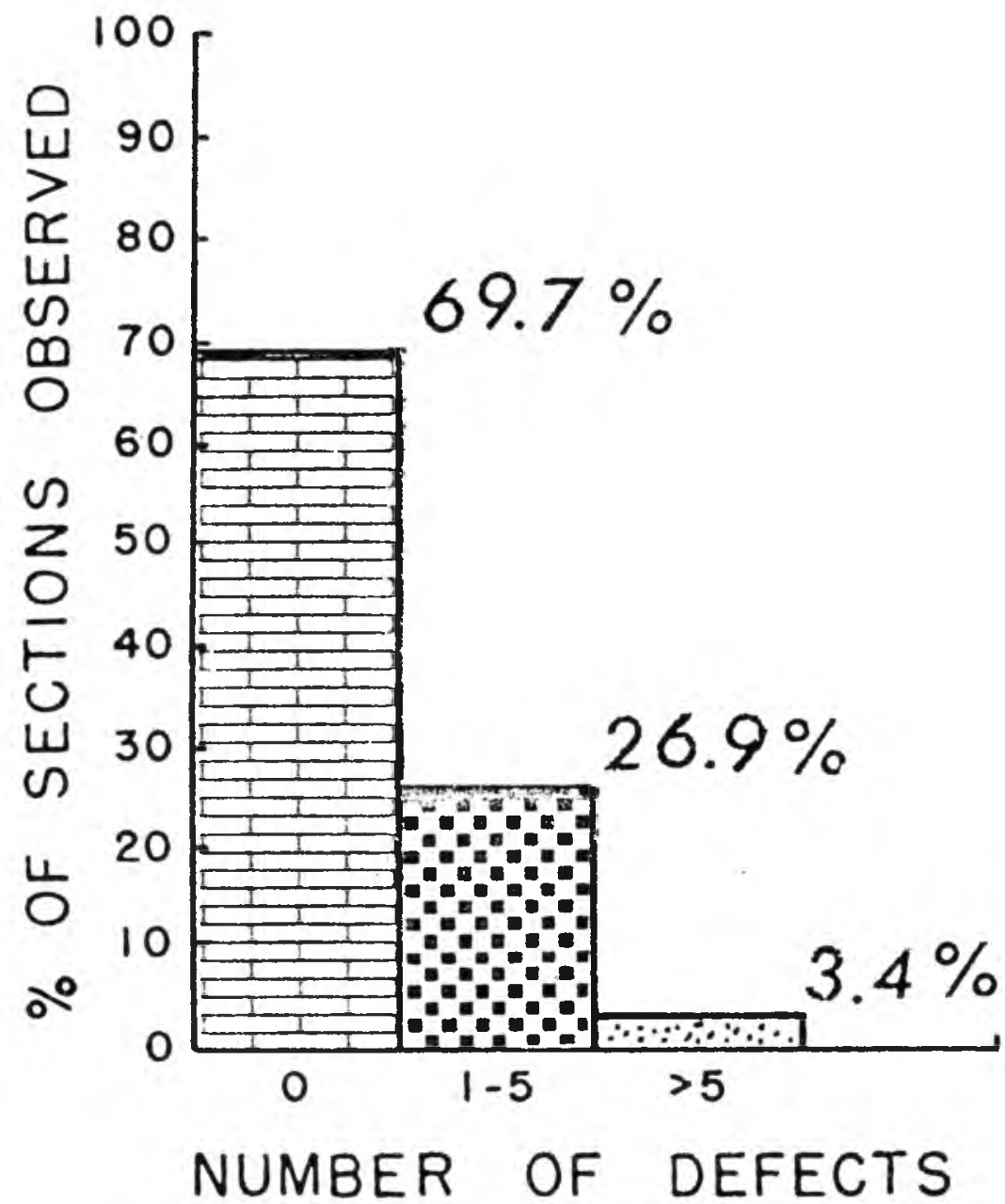

Fig. 3. Frequency Distribution of Defects Observed in the Statewide CRCP Survey

1. Subgrade. The results have suggested that subgrade type (granular or fine-grained) was not a significant contributor to performance of CRC pavements.

2. Subbase Type. Subbase type was found to be a significant contributor to performance of CRC pavements, with gravel subbases showing the poorest performance. Crushed stone subbases have, in general, shown good performance and up to the time of the survey the bituminous stabilized subbases showed little or no distress. However, since the survey was conducted, some breakup has been encountered on at least one bituminous stabilized subbase. 
3. Method of Steel Placement. Depressed steel was shown to have significantly better performance than preset steel used on chairs.

4. Steel Fabrication. All other factors being constant (type of subbase, method of construction, etc.), loose bars and welded wire fabric have shown good performance. Bar mats showed the poorest performance, but as was pointed out earlier, this type of steel was used only on some of the earlier projects, and thus, these pavements have been exposed to a wider range of environmental and traffic conditions.

5. Method of Paving. The data showed little difference between performance of pavements that were constructed using side forms compared to those which were slipformed.

6. Traffic. Distress of CRC pavements is associated with traffic and apparently is on the increase in Indiana.

7. Concrete Slump. Concrete slump has a significant effect on pavement performance with an apparent optimum slump between 2.0 to 2.5 inches. Slump of 1.5 inches and greater have shown good results.

8. Temperature. It has been observed that much of the distress takes place during the cold months of the year, suggesting that extreme temperature drops have a major effect on performance. 